\title{
Redes de Freqüência Única Microrregionais
}

\author{
Renato de Melo Faria e Maurício Silveira
}

\begin{abstract}
Resumo-O uso de redes de frequiência única $(S F N)$ para transmissão de TV digital no Brasil foi viabilizado a partir da decisão do governo brasileiro em utilizar o padrão ISDB-T (Integrated Services Digital Broadcasting Terrestrial) em seu Sistema Brasileiro de Televisão Digital Terrestre (SBTVD-T), [3]. O ISDB-T usa em seu esquema de Modulação a Transmissão Segmentada de Banda com Multiplexação Ortogonal das Frequiências (Band Segmented Transmission Orthogonal Frequency Division Multiplexing (BST-OFDM). Este artigo apresenta uma proposta inovadora de implementação de redes $S F N$ com o objetivo de aumentar a eficiência do uso do espectro. Será apresentado um estudo de viabilidade de implementação de uma rede $S F N$ na microrregião de Campinas, cidade localizada no Estado de São Paulo com o propósito principal de mensurar todos os ganhos obtidos na transmissão.
\end{abstract}

Palavras-Chave-Otimização de Espectro, Redes de Freqüência Única $(S F N)$, Planejamento de Cobertura de RF, TV Digital.

Abstract- The use of Single Frequency Networks (SFN) for transmission of digital TV in Brazil was made possible from the decision of the Brazilian government in using standard ISDB-T (Integrated Services Digital Broadcasting Terrestrial) in its Brazilian System of Terrestrial Digital Television (SBTVD-T), [3]. The ISDB-T uses in its project of modulation the Band Segmented Transmission - Orthogonal Frequency Division Multiplexing (BST-OFDM). This article presents an innovative proposal of implementation of a $S F N$ network with the objective to increase the efficiency of the use of the spectrum. A feasibility study of implementation of a $S F N$ net in the microregion of Campinas, city located in the São Paulo State, will be presented with the final purpose to measure all obtained gains in the transmission.

Index Terms-Spectrum Optimization, Single Frequency Networks ( $S F N$ ), Planning of Covering of RF, Digital TV.

\section{INTRODUÇÃO}

O planejamento de inclusão e alteração de canais de televisão analógica leva em consideração uma estrutura de rede MFN (Multi Frequency Network). Redes MFN pressupõem a alocação de canais diferentes para distribuir uma mesma programação e somente permitem o reuso da freqüência desde que haja uma separação geográfica suficiente para que as estações não se interfiram. Classicamente, a estrutura $S F N$ é a configuração de uma rede que distribui a mesma programação no mesmo canal e, portanto, possui características restritivas específicas para seu funcionamento.

Estas restrições são, basicamente, transmitir a mesma programação, na mesma freqüência, em instante de tempo controlado e ainda sob condições de distanciamento entre os transmissores que não excedam certos limites.

Renato de Melo Faria, Mestrando em Gestão de Telecomunicações, Fundação $\mathrm{CPqD}$ e Pontifícia Universidade Católica de Campinas, (renatodemelofaria@gmail.com); Maurício Silveira, Pontifícia Universidade Católica de Campinas e IEEE Senior Member (msilveira@puc-campinas.edu.br).
Podem ser atribuídos como principais benefícios às redes $S F N$ o seu alto poder de otimização de espectro, a necessidade de potências de transmissão menores e o aumento da diversidade de transmissão. Entretanto, as redes SFN necessitam de um controle rigoroso em relação ao sincronismo de tempo e freqüência de transmissão, [7,8].

$\mathrm{O}$ atual plano básico de radiodifusão terrestre digital (PBTVD), que originou a criação das redes $S F N$, foi planejado levando-se em consideração o reuso de canais somente quando da impossibilidade de alocação de um novo canal digital em uma determinada localidade, [4]. Esta diretriz levou a um planejamento que não usou como premissa básica a capacidade de formação de redes $S F N$, o que acabou por reduzir a possibilidade de otimização do espectro.

Este artigo propõe no âmbito do território nacional que cada emissora possa utilizar somente um canal digital por microrregião. Esta diretriz faz com que a otimização de espectro seja bastante significativa atendendo o anseio do poder público para aumento da eficiência de utilização do espectro, demanda esta imposta fortemente no presente momento com o surgimento de novas tecnologias para os sistemas de HDTV e as correspondentes alocações em faixas espectrais de uma forma otimizada.

$\mathrm{Na}$ seção II serão apresentados os aspectos regulatórios que envolvem a definição do $S B T V D-T$ e que tem impacto no planejamento de canais de TV Digital. Na seção III será apresentada de forma sucinta, os aspectos técnicos que envolvem a tecnologia das redes SFN. Na seção IV serão apresentadas as premissas que nortearam a elaboração do atual PBTVD. Na seção V será apresentado o resultado do planejamento de redes SFN na microrregião de Campinas que leva em consideração a estratégia de alocar somente um canal por emissora dentro de uma mesma microrregião. $\mathrm{Na}$ seção VI serão apresentadas as conclusões sobre o tema abordado neste artigo.

\section{Aspectos REgUlAtóRIOS}

O decreto $\mathrm{n}^{\mathrm{o}} 4.901$, de 26 de novembro de 2003, que instituiu o $S B T V D-T$, indica a preocupação do poder público em aperfeiçoar o uso do espectro de radiofrequiências, [1]. Esta necessidade se baseia no fato de que o espectro de radiofrequiência é um bem finito e, portando, de grande valia para a sociedade. Apesar de existirem disponíveis 12 canais em $V H F$ (canais 2 ao 13) e 44 canais em $U H F$ (canais 14 ao 59, excetuando o canal 37) para transmissão e retransmissão de canais de televisão aberta, nas regiões de alta densidade urbana, já encontramos uma grande dificuldade para alocação de novos canais por conta de interferências que seriam provocadas em canais já previamente estabelecidos.

Com as normativas estabelecidas na publicação do decreto $\mathrm{n}^{\circ}$ 5.820, de 29 de Junho de 2006, que fixa as diretrizes para a transição do sistema de transmissão analógica para àquele de transmissão digital nos serviços de 
radiodifusão de sons e imagem, assim como na retransmissão dos sinais de televisão, haverá um período de transição de 10 anos onde haverá transmissão simultânea da programação analógica e digital [3]. Esta condição de transmissão simultânea faz com que o espectro, que já se encontrava congestionado pela transmissão analógica das atuais emissoras, fique ainda mais congestionado por conta da adição das novas transmissões digitais.

Contratado pela ANATEL, o CPqD realizou o planejamento de viabilização de canais de TV Digital em todo o território nacional. Neste planejamento foram viabilizados 1893 canais em 290 municípios [5]. Como critério de planejamento, foi utilizada a premissa de somente lançar mão do reuso de freqüência na impossibilidade de uso de canais viáveis, [4].

O decreto acima citado indica também, a obrigatoriedade de alocar mais quatro canais de seis (06) Megahertz nos 290 municípios contemplados no PBTVD para a exploração direta pela União Federal, com os Canais alocados para: o Poder Executivo, a Educação, o da Cultura e o da Cidadania, [3]. Isto reforça ainda mais a necessidade do estudo ora feito de otimização do espectro, afim de que seja provida esta nova demanda na banda de freqüências.

O SBTVD-T deverá possibilitar a transmissão digital simultânea para recepção fixa, móvel e portátil, [3]. Para a melhor performance de recepção móvel e portátil é desejável que haja diversidade de sinais. Um dos grandes benefícios associados à criação de redes $S F N$, além do aumento da eficiência de uso do espectro, é justamente a criação de uma área de serviço com diversidade de transmissão.

Os aspectos regulatórios descritos nesta seção indicam a necessidade de implantação de estruturas de redes que aumentem a eficiência do espectro, sempre que possível.

\section{REDES $S F N$}

Esta seção trata de uma descrição sucinta dos principais aspectos técnicos envolvendo as tecnologias das redes $S F N$. Estas são caracterizadas por transmitirem a mesma programação, na mesma freqüência, em um tempo controlado e dentro de certas condições de espaçamento das estações transmissoras, que viabilizem as transmissões demandadas. A estrutura das redes $S F N$ está fundamenta nas arquiteturas de modulação $O F D M$ por conta da introdução de intervalos de guarda $\left(t_{g}\right)$ que eliminam o efeito de dispersão causado pelos multipercursos dos sinais.

Nakahara et al, elaboraram um estudo que apresenta um resultado expressivo de mais de $97 \%$ de cobertura utilizando-se um único canal, em uma demanda necessária superior a 30 canais analógicos para cobrir a mesma área. Isto demonstra o alto grau de otimização alcançado quando da utilização deste tipo de estrutura de rede [6].

A interação de sinais que chegam a um determinado receptor provenientes das reflexões de uma onda transmitida e/ou oriundos de diversos transmissores operando na mesma frequiência, podem causar uma degradação do sinal por conta da interferência inter-simbólica (Intersymbol Interference - ISI). Esta interferência é eliminada, dentro de certos limites, pela introdução do artifício do intervalo de guarda $\left(t_{g}\right)$. Este parâmetro fixa o intervalo de tempo que é colocado no início da transmissão de cada símbolo, sem que o transmissor possa ser transmitido qualquer sinal útil. Toda a informação contida dentro do intervalo de guarda é descartada no receptor, eliminando assim a interferência que um símbolo causa em seu sucessor.

$\mathrm{O}$ atraso de um determinado sinal é função da distância que este sinal percorre e pode ser expresso pela seguinte relação:

$$
\Delta t=\frac{\Delta d}{c}=\frac{\Delta d(m)}{3 * 10^{8} \mathrm{~m} / \mathrm{s}}
$$

Para o caso de termos uma distância de $1 \mathrm{~km}$, temos de acordo com (1) um atraso de $3,33 \mu \mathrm{s}$; ou seja, um sinal atrasa aproximadamente $3,33 \mu \mathrm{s}$, em relação à sua referência, a cada quilômetro percorrido.

Na Tabela I é apresentada a performance do sistema onde são indicadas quais os atrasos máximos permitidos em função das configurações do sistema ISDB-T.

TABELA I

PARÂMETROS DO SEGMENTO OFDM

\begin{tabular}{|c|c|c|c|}
\multicolumn{1}{|c}{ PARÂMETROS DO SEGMENTO OFDM } \\
\hline MODO & MODO 1 & MODO 2 & MODO 3 \\
\hline \hline $\begin{array}{c}\text { ESPAÇAMENTO } \\
\text { ENTRE AS } \\
\text { FREQÜÊNCIAS }\end{array}$ & $250 / 63$ & $125 / 63$ & $125 / 126$ \\
\hline TAMANHO & & & \\
EFETIVO DO & $252 \mu \mathrm{s}$ & $504 \mu \mathrm{s}$ & $1008 \mu \mathrm{s}$ \\
SÍMBOLO & & & \\
\hline & $63 \mu \mathrm{s}(1 / 4)$ & $126 \mu \mathrm{s}(1 / 4)$ & $252 \mu \mathrm{s}(1 / 4)$ \\
INTERVALO DE & $31,5 \mu \mathrm{s}(1 / 8)$ & $63 \mu \mathrm{s}(1 / 8)$ & $126 \mu \mathrm{s}(1 / 8)$ \\
GUARDA & $15,75 \mu \mathrm{s}(1 / 16)$ & $31,5 \mu \mathrm{s}(1 / 16)$ & $63 \mu \mathrm{S}(1 / 16)$ \\
& $7,875 \mu \mathrm{s}(1 / 32)$ & $15,75 \mu \mathrm{s}(1 / 32)$ & $31,5 \mu \mathrm{s}(1 / 32)$ \\
\hline
\end{tabular}

Os modos 1, 2 e 3 encontrados na Tabela I, correspondem aos espaçamentos de $4 \mathrm{kHz}, 2 \mathrm{khz}$ e $1 \mathrm{kHz}$, respectivamente, e também são identificados como modos $2 \mathrm{~K}, 4 \mathrm{~K}$ e $8 \mathrm{~K}$. Esta última designação está relacionada à quantidade de portadoras de cada um dos modos em um canal de $6 \mathrm{MHz}$, [9].

Verifica-se pela Tabela I que o sistema ISDB-T propicia configurações de intervalo de guarda de até $252 \mu$ s, isto é: $t_{g}$ $=1 / 4$ no modo 3 de transmissão. Neste caso, é possível regenerar sinais que chegam a um receptor e que tenham uma diferença de distância percorrida de aproximadamente 75,6 quilômetros. Utilizando-se intervalo de guarda de até $7,875 \mu \mathrm{s}$, que corresponde a $t_{g}=1 / 32$ no modo $1 \mathrm{de}$ transmissão, é possível regenerar sinais que chegam a um receptor que tenham uma diferença máxima de distância percorrida de aproximadamente 2,4 quilômetros.

Conforme demonstrado na Tabela II, alguns parâmetros do $I S D B-T$ devem ajustados de acordo com o programa que se pretende transmitir. Normalmente, existe o compromisso entre o aumento de taxa de transmissão e a robustez do sinal.

Em [3] foi normatizado que o $S B T V D-T$ deverá disponibilizar:

- TV em alta definição: que requer altas taxas de transmissão;

- Mobilidade: que requer modos de transmissão mais robustos e modos de transmissão com menos portadoras por conta do efeito doppler;

- Melhor uso do espectro: que ao pressupor a configuração de redes $S F N$ requer intervalos de guarda maiores, os quais são dependentes das distâncias entre as estações transmissoras. Conseqüentemente, deverá ocorrer a necessidade na transmissão dos modos com mais portadoras. 
TABELA II

PARÂMETROS DE CONFIGURAÇÃO OFDM

\begin{tabular}{|c|c|c|}
\hline Parâmetro & Menor & Maior \\
\hline $\begin{array}{c}\text { Modos de } \\
\text { transmissão } \\
\text { Tipos: } 1,2 \text { ou } \\
3\end{array}$ & $\begin{array}{c}\text { Maior robustez } \\
\text { referente a efeito } \\
\text { Doppler (mobilidade) } \\
\text { Menor sensibilidade } \\
\text { a variações de } \\
\text { freqüência }\end{array}$ & $\begin{array}{c}\text { Proporciona } \\
\text { Intervalos de } \\
\text { guarda } \\
\text { maiores }\end{array}$ \\
\hline $\begin{array}{c}\text { Intervalo de } \\
\text { guarda:1/4, } \\
1 / 8,1 / 16 \text { ou } \\
1 / 32\end{array}$ & $\begin{array}{l}\text { Aumento da taxa de } \\
\text { transmissão }\end{array}$ & $\begin{array}{c}\text { Maior } \\
\text { imunidade à } \\
\text { multi- } \\
\text { percursos }\end{array}$ \\
\hline $\begin{array}{c}\text { Código } \\
\text { Convolucional: } \\
\text { 1/2, } 2 / 3,3 / 4 \text {, } \\
5 / 6,7 / 8\end{array}$ & $\begin{array}{c}\text { Aumento da robustez } \\
\text { do sinal }\end{array}$ & $\begin{array}{l}\text { Aumento da } \\
\text { taxa de } \\
\text { transmissão }\end{array}$ \\
\hline $\begin{array}{l}\text { Modulação das } \\
\text { portadoras: } \\
D Q P S K, \\
Q P S K, 16 Q A M \\
\text { ou } 64 Q A M\end{array}$ & $\begin{array}{c}\text { Aumento da robustez } \\
\text { do sinal }\end{array}$ & $\begin{array}{l}\text { Aumento da } \\
\text { taxa de } \\
\text { transmissão }\end{array}$ \\
\hline
\end{tabular}

Para atender a todas estas indicações, com boa performance, ainda restam várias configurações possíveis que devem ser usadas de acordo com a necessidade específica de cada caso. As configurações que atendem taxas acima de $18 M b p s$, que é uma demanda suficiente para transmissão de sinais de HDTV estão destacados na Tabela III, [7], [9].

TABELA III

PARÂMETROS DE CONFIGURAÇÃO $O F D M$

\begin{tabular}{|c|c|c|c|c|c|}
\hline \multirow{2}{*}{$\begin{array}{c}\text { Tipo de } \\
\text { Modu- } \\
\text { lação }\end{array}$} & $\begin{array}{c}\text { Código } \\
\text { Convolu- } \\
\text { cional }\end{array}$ & \multicolumn{4}{|c|}{ Taxa (Mbps) } \\
\cline { 3 - 6 } & $\begin{array}{c}\mathrm{t}_{\mathrm{g}}: \\
1 / 4\end{array}$ & $\begin{array}{c}\mathrm{t}_{\mathrm{g}}: \\
1 / 8\end{array}$ & $\begin{array}{c}\mathrm{t}_{\mathrm{g}}: \\
1 / 16\end{array}$ & $\begin{array}{c}\mathrm{t}_{\mathrm{g}}: \\
1 / 32\end{array}$ \\
\hline \multirow{3}{*}{$64 Q A M$} & $3 / 4$ & 16,4 & $\underline{\mathbf{1 8 , 3}}$ & $\underline{\mathbf{1 9 , 3}}$ & $\underline{\mathbf{1 9 , 9}}$ \\
\cline { 2 - 6 } & $5 / 6$ & $\underline{\mathbf{1 8 , 3}}$ & $\underline{\mathbf{2 0 , 3}}$ & $\underline{\mathbf{2 1 , 5}}$ & $\underline{\mathbf{2 2 , 1}}$ \\
\cline { 2 - 6 } & $7 / 8$ & $\underline{\mathbf{1 9 , 2}}$ & $\underline{\mathbf{2 1 , 3}}$ & $\underline{\mathbf{2 2 , 6}}$ & $\underline{\mathbf{2 3 , 2}}$ \\
\hline
\end{tabular}

\section{Plano BÁsico de Distribuição de CANAIS DE TELEVISÃO DIGITAL - PBTVD}

O PBTVD, através da resolução $\mathrm{n}^{\circ}$ 407, de 10 de junho de 2005, foi elaborado para acomodar os canais de televisão nos principais municípios brasileiros. Os municípios que foram contemplados com o planejamento coordenado neste planejamento da ANATEL foram os que continham pelo menos uma geradora ativa, os municípios que tinham pelo menos 100.000 habitantes atendidos por retransmissoras ativas e finalmente os municípios atendidos por estações localizadas em pontos de transmissão próximos aos adotados por canais considerados nas duas situações anteriormente descritas. Dentro deste escopo, foram viabilizados 1893 canais em 290 municípios, [5].

Para atender a premissa de replicar a cobertura dos canais analógicos, os canais digitais foram viabilizados, sempre que tecnicamente possível, com a potência máxima da classe à qual pertence o canal analógico, [4]. Esta premissa não leva em consideração qual a motivação que levou a incluir um novo canal analógico, o que poderia ser fruto de otimização, caso a inclusão tenha sido feita para tão somente cobrir uma pequena área de sombra do transmissor principal. A Tabela IV demonstra a relação da potência máxima em canais analógicos por classe e o nível correspondente de potência máxima, quando for considerado o planejamento de canal digital. Esta relação é para garantir que a distância máxima ao contorno protegido dos canais digitais seja a mesma dos canais analógicos. A relação de potência é aproximadamente de $-13 \mathrm{~dB}$ do canal digital em relação ao canal analógico.

TABELA IV

ClASSIFICAÇÃO DE POTÊNCIA DE ESTAÇÕES

\begin{tabular}{|c|c|c|c|c|c|}
\hline \multirow{2}{*}{$\begin{array}{c}\text { Clas- } \\
\text { ses }\end{array}$} & Canais & $\begin{array}{c}\text { Potência } \\
\text { Máx } \\
\text { (Digital) }\end{array}$ & $\begin{array}{c}\text { Potência } \\
\text { Máx. } \\
\text { (Analóg.) }\end{array}$ & $\begin{array}{c}\text { Altura } \\
\text { de } \\
\text { Refe- } \\
\text { rência }\end{array}$ & $\begin{array}{c}\text { Distância } \\
\text { Máxima } \\
\text { ao } \\
\text { Contorno } \\
\text { Protegido }\end{array}$ \\
\hline \multirow{2}{*}{ Esp. } & 14 ao 25 & $60 \mathrm{~kW}$ & & & \\
\cline { 2 - 4 } & 26 ao 46 & $70 \mathrm{~kW}$ & $1600 \mathrm{~kW}$ & & $57 \mathrm{~km}$ \\
\cline { 2 - 3 } & 47 ao 59 & $100 \mathrm{~kW}$ & & \multirow{2}{*}{$150 \mathrm{~m}$} & \\
\cline { 1 - 3 } A & 14 ao 59 & $8 \mathrm{~kW}$ & $160 \mathrm{~kW}$ & & $42 \mathrm{~km}$ \\
\hline B & 14 ao 59 & $0,8 \mathrm{~kW}$ & $16 \mathrm{~kW}$ & & $29 \mathrm{~km}$ \\
\hline C & 14 ao 59 & $0,08 \mathrm{~kW}$ & $1,6 \mathrm{~kW}$ & & $18 \mathrm{~km}$ \\
\hline
\end{tabular}

A intensidade de campo mínima para recepção é função do tipo de parâmetro utilizado no sistema. Para as simulações que serão realizadas neste artigo, adotaremos o nível mínimo de recepção de sinais com antena externa de $50(d B \mu V / m)$ e com antena interna de $60(d B \mu V / m)$. Recomenda-se adotar o nível de intensidade de campo de 43 $(d B \mu V / m)$ para $V H F$ alto (canais 7 a 13$)$ e $51(\mathrm{~dB} \mu \mathrm{V} / \mathrm{m})$ para $U H F$ na proteção dos canais digitais [4].

Outro aspecto técnico importante para o planejamento de inclusão dos canais digitais são as relações de proteção que devem ser respeitadas para evitar interferências mútuas no canal proposto e nos canais existentes.

TABELA V

RELAÇÕES DE PROTEÇÃO

\begin{tabular}{|c|c|c|c|c|}
\hline \multirow[b]{2}{*}{$\begin{array}{c}\text { Canal } \\
\text { Interferente }\end{array}$} & \multicolumn{4}{|c|}{ Relação D/U (dB) (Canal desejado) } \\
\hline & $\begin{array}{l}\text { Analógico } \\
\text { sobre } \\
\text { Analógico }\end{array}$ & $\begin{array}{c}\text { Digital } \\
\text { sobre } \\
\text { Analógico }\end{array}$ & $\begin{array}{c}\text { Analógico } \\
\text { sobre } \\
\text { Digital } \\
\end{array}$ & $\begin{array}{c}\text { Digital } \\
\text { Sobre } \\
\text { Digital } \\
\end{array}$ \\
\hline $\mathrm{N}-1$ & -6 & -11 & -26 & -24 \\
\hline \multirow{2}{*}{$\mathrm{N}$} & $\begin{array}{l}28 \text { (com } \\
\text { decalag.) }\end{array}$ & \multirow{2}{*}{34} & \multirow{2}{*}{7} & \multirow{2}{*}{19} \\
\hline & $\begin{array}{l}45 \text { (sem } \\
\text { decalag. }\end{array}$ & & & \\
\hline $\mathrm{N}+1$ & -12 & -11 & -26 & -24 \\
\hline $\mathrm{N}-8$ e $\mathrm{N}+8$ & -12 & -25 & & \\
\hline $\mathrm{N}-7$ e $\mathrm{N}+7$ & -6 & -24 & & \\
\hline $\mathrm{N}+14$ & -6 & -24 & & \\
\hline $\mathrm{N}+15$ & -3 & -22 & & \\
\hline
\end{tabular}

Estas relações de proteção estão descritas na Tabela V. Nesta identifica-se que os canais digitais são menos susceptíveis a interferências, mas devido à condição de transmissão simultânea de sinais digitais e analógicos, o planejamento de inclusão de canais digitais tem que levar em consideração todas as restrições impostas pela susceptibilidade à interferência dos canais analógicos. Desta forma, as redes $S F N$ em grande áreas se tornam praticamente inviáveis, por conta do aumento da probabilidade de existir 
alguma violação de proteção à medida em que a rede cresce, principalmente durante a fase de transmissão simultânea de sinais digitais e analógicos.

A elaboração do PBTVD utilizou modelos de propagação ponto-área e modelos de propagação ponto-a-ponto [4]. Os modelos ponto-área demonstram viabilidade principalmente onde não existe um congestionamento específico do espectro. Em regiões de alta densidade espectral, normalmente utiliza-se o método ponto-a-ponto por conta de sua maior precisão na determinação de campo.

\section{Planejamento de Redes SFN NA Microrregião dE CAMPINAS}

Para demonstrar os benefícios trazidos pelo planejamento de Redes $S F N$ microrregionais, foi escolhida a microrregião de Campinas, localizada no estado de São Paulo. De acordo com o IBGE, esta microrregião congrega 16 municípios: Américana, Campinas, Cosmópolis, Elias Fausto, Holambra, Hortolândia, Indaiatuba, Jaguariúna, Monte Mor, Nova Odessa, Paulínia, Pedreira, Santa Bárbara d'Oeste, Sumaré, Valinhos e Vinhedo. Esta microrregião perfaz uma população de 2.530.029 habitantes, com área total de $3.082,952 \mathrm{~km}^{2}$ e com um PIB/per capta de R $\$ 18.275,69$ (IBGE/2003), o que demonstra sua importância no cenário brasileiro. A Figura 1 mostra o mapa desta microrregião.

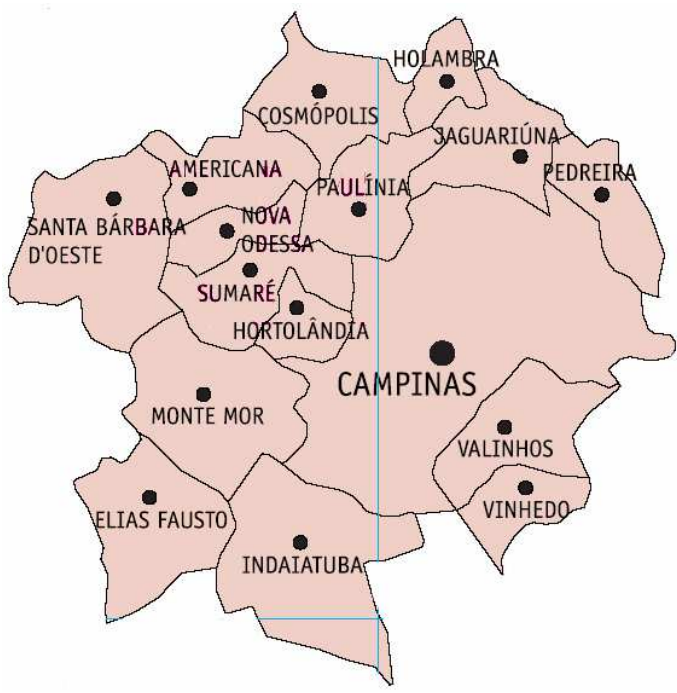

Fig. 1. Mapa da microrregião de Campinas

De acordo com o PBTVD, existe a previsão de utilização de cinco canais com reuso em Campinas/Valinhos e outros 5 em Santa Bárbara D’Oeste/Limeira. Esta informação indica que a microrregião de Campinas já sofre de congestionamento de espectro, dado que no planejamento do PBTVD somente lançava-se mão do reuso de canais quando da impossibilidade de alocação de um novo canal naquela localidade.

Vale reiterar que no plano básico ainda deverão ser viabilizados nas localidades que foram contempladas no PBTVD, pelo menos mais quatro canais digitais para a exploração direta pela União Federal, [2].

De acordo com a Tabela VI, dos 290 municípios contemplados no planejamento do PBTVD, sete deles estão dentro da microrregião de Campinas: Americana, Campinas, Hortolândia, Indaiatuba, Santa Bárbara D'Oeste, Sumaré e
Valinhos, com um total de 28 canais alocados.

TABELA VI

Distribuições de CANAIS POR PLANOS BÁSICOS PARA A MicRORREGIÃo DE CAMPINAS

\begin{tabular}{|l|c|c|}
\hline \multicolumn{1}{|c|}{ Município/Plano } & PBTV/ PBRTV & PBTVD \\
\hline Americana & 2 & 2 \\
\hline Campinas & 11 & 11 \\
\hline Cosmópolis & & \\
\hline Elias Fausto & 2 & - \\
\hline Holambra & 1 & 1 \\
\hline Hortolândia & 1 & 1 \\
\hline Indaiatuba & 1 & - \\
\hline Jaguariuna & & \\
\hline Monte Mor & 1 & - \\
\hline Nova Odessa & 2 & - \\
\hline Paulínia & 6 & 6 \\
\hline Pedreira & 1 & 1 \\
\hline Santa Bárbara d'Oeste & 6 & 6 \\
\hline Sumaré & 1 & - \\
\hline Valinhos & 35 & 28 \\
\hline Vinhedo & & \\
\hline \hline Total & & \\
\hline
\end{tabular}

Os canais dos municípios de Americana e Campinas foram viabilizados por conta destes municípios terem estações de geração ativas. Os canais dos municípios de Hortolândia, Indaiatuba, Santa Bárbara D'Oeste e Sumaré foram viabilizados por conta que estes municípios tem pelo menos 100 mil habitantes atendidos por retransmissoras ativas. Finalmente, os canais de Valinhos foram viabilizados por conta de que este município é atendido por estação localizada em ponto de transmissão próximo ao adotado por canais considerados nas premissas anteriores, sendo que Valinhos é atendido por Campinas.

As cidades de Cosmópolis, Elias Fausto, Monte Mor e Nova Odessa não possuíam nenhum canal analógico e não foram tiveram nenhum canal alocado no PBTVD.

As cidades de Holambra, Jaguariúna, Paulínia, Pedreira, e Vinhedo possuem sete canais alocados no plano básico de retransmissão de TV (PBRTV) e não tiveram nenhum canal alocado no PBTVD por não atenderem às premissas que identificavam os municípios que entrariam no foco deste planejamento. Um estudo posterior pode ser feito no planejamento para viabilizar os demais canais nos municípios que não foram viabilizados segundo as premissas descritas, [4].

A Tabela VII relaciona a quantidade de canais analógicos e digitais alocado para cada uma das emissoras que tenham alguma transmissão ou retransmissão de sinais na microrregião de Campinas. Esses dados foram levantados através do Sistema de Controle de Radiodifusão, disponibilizado pela ANATEL em sua página na Internet e demonstra que os 35 canais utilizados na microrregião de Campinas atendem a 15 programações distintas. Caso seja tecnicamente possível alocar somente um canal para cada emissora dentro da microrregião de Campinas, teríamos, no limite, somente a necessidade de 15 canais operando em SFN para acomodar todas as emissoras. 
TABELA VII

QUANTIDADE DE CANAIS UTILIZADOS POR GERADORA NA MICRORREGIÃO DE CAMPINAS - PLANO BÁSICO: TV ANALÓGICA E DIGITAL

\begin{tabular}{|c|c|l|}
\hline \multicolumn{2}{|c|}{ Qtde Canais } & \multicolumn{2}{|}{ Fistel da Geradora } \\
\cline { 1 - 2 } Analog. & Digit. & \multicolumn{1}{|c|}{} \\
\hline 2 & 2 & Canal Brasileiro da Informação CBI \\
\hline 3 & 3 & Empresa Paulista de Televisão \\
\hline 1 & 1 & Fundação Cásper Líbero \\
\hline 7 & 3 & Fundação Padre Anchieta \\
\hline 3 & 2 & Fundação Século Vinte e Um \\
\hline 1 & 1 & Rádio e Televisão Bandeirantes \\
\hline 3 & 3 & Rádio e Televisão Record \\
\hline 2 & 2 & $\begin{array}{l}\text { Rádio e Televisão Bandeirantes de } \\
\text { Campinas }\end{array}$ \\
\hline 3 & 3 & Radiobrás \\
\hline 1 & 1 & Rede Família de Comunicação \\
\hline 1 & 1 & Televisão Cachoeira do Sul \\
\hline 2 & 1 & $\begin{array}{l}\text { Televisão Independente de São José do } \\
\text { Rio Preto }\end{array}$ \\
\hline 3 & 2 & Televisão Princesa D’Oeste \\
\hline 2 & 2 & TV Carioba \\
\hline 1 & 1 & TV Ômega \\
\hline 35 & 28 & \\
\hline
\end{tabular}

$\mathrm{O}$ foco principal deste artigo se concentra no remanejamento dos canais no PBTVD para que estes formem redes $S F N$ de tal forma que teríamos uma redução de 28 para 15 canais digitais utilizados para a transmissão ou a retransmissão das 15 emissoras presentes na microrregião de Campinas. Considere-se que já existe a previsão de reuso de 5 canais na interface Campinas/Valinhos.

A seguir, será apresentada a designação dos canais para as emissoras, bem como os arranjos necessários para a implementação da redes $S F N$ de forma a atender o cenário onde cada emissora utilizaria somente um único canal digital na microrregião de Campinas. Na Tabela VIII estão indicados os canais viabilizados na microrregião de Campinas no planejamento do PBTVD, bem como as potências alocadas para cada um deles.

Os canais sublinhados na Tabela VIII indicam quais foram os canais liberados após a aplicação da estratégia de alocação de canais aqui proposta. A viabilidade de alocação de canais foi realizada através de simulação computacional e levou em consideração o método ponto-a-ponto, uma resolução de cálculo menor ou igual a 100 metros e uma potência efetiva irradiada $(E R P)$ com a máxima potência permitida para a classe de potência designada para o canal em estudo. Apresentamos um exemplo de tela de configuração do software de simulação na Figura 2.

No PBTVD não foram indicados quais os canais estão alocados as emissoras. Como no planejamento do PBTVD foi fixada a premissa que os canais digitais deveriam ser viabilizados de tal forma a replicar a cobertura dos canais analógicos, neste artigo está sendo imposta a condição da alocação canal/emissora baseada na potência de transmissão digital necessária para a mesma classe de potência no analógico. Um outro item que levamos em consideração está ligado ao fato que a atribuição de canal/emissora deveria facilitar a implementação das redes $S F N$ [4].
TABELA VIII

CANAL/POTÊNCIA VIABILIZADOS NO PBTVD

\begin{tabular}{|c|c|c|}
\hline Município & Canal & $\begin{array}{c}\text { ERP Max } \\
(\mathbf{K W})\end{array}$ \\
\hline Americana & $\underline{\mathbf{2 1}, \underline{\mathbf{2 7}}}$ & 0,080 \\
\hline Campinas & $9,13,19$ & 1,580 \\
\hline Campinas & $16,24,29,42,50,59$ & 8,000 \\
\hline Campinas & 30,54 & 0,800 \\
\hline Hortolândia & $\underline{\mathbf{1 7}}$ & 0,080 \\
\hline Indaiatuba & $\underline{\mathbf{4 0}}$ & 0,080 \\
\hline $\begin{array}{c}\text { Santa Bárbara } \\
\text { D'Oeste }\end{array}$ & $15,25, \underline{\mathbf{3 8}}, 44,50,59$ & 0,080 \\
\hline Sumaré & $\underline{\mathbf{5 1}}$ & 0,080 \\
\hline Valinhos & 13 & 0,158 \\
\hline Valinhos & $16,29,39,42,50$ & 0,800 \\
\hline
\end{tabular}

TABELA IX

ALOCAÇÃO INICIAL DOS CANAIS / EMISSORA / LOCALIDADE

\begin{tabular}{|c|c|}
\hline Americana & $\begin{array}{l}\text { Radiobrás }(\underline{\mathbf{2 1}}) \\
\text { TV Carioba }(\underline{\mathbf{2 7}})\end{array}$ \\
\hline Campinas & $\begin{array}{l}\text { Rede Família de Comunicação (9) } \\
\text { Empresa Paulista de Televisão (13) } \\
\text { Fundação Cásper Líbero (19) } \\
\text { Rádio e Televisão Bandeirantes de } \\
\text { Campinas (16) } \\
\text { TV Carioba (24) } \\
\text { Canal Brasileiro da Informação (29) } \\
\text { Televisão Princesa D’Oeste (42) } \\
\text { Record (50) } \\
\text { Fundação Padre Anchieta (59) } \\
\text { Televisão Independente de São José do } \\
\text { Rio Preto (30) } \\
\text { Fundação Século Vinte e Um (54) }\end{array}$ \\
\hline Hortolândia & Fundação Padre Anchieta (17) \\
\hline Indaiatuba & 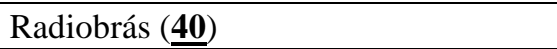 \\
\hline $\begin{array}{c}\text { Santa Bárbara } \\
\text { D'Oeste }\end{array}$ & 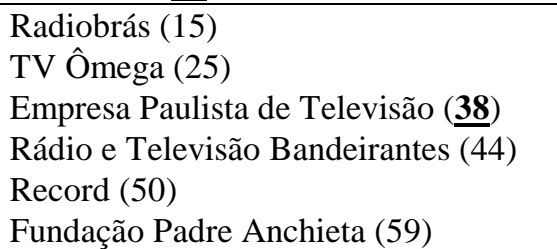 \\
\hline Sumaré & 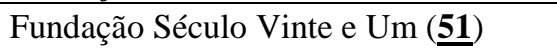 \\
\hline Valinhos & $\begin{array}{l}\text { Empresa Paulista de Televisão (13) } \\
\text { Rádio e Televisão Bandeirantes de } \\
\text { Campinas (16) } \\
\text { Canal Brasileiro da Informação (29) } \\
\text { Televisão Cachoeira do Sul (39) } \\
\text { Televisão Princesa D'Oeste (42) } \\
\text { Record (50) }\end{array}$ \\
\hline
\end{tabular}

A Tabela IX indica a alocação inicial de canais digitais/emissoras para cada localidade na microrregião de Campinas. Esta alocação foi feita com base nas potências que cada emissora deve transmitir para que tenha a mesma cobertura de transmissão digital e analógica. As indicações em destaque nesta tabela indicam quais os canais devem ser remanejados para possibilitar que cada emissora ocupe somente um canal em toda a microrregião de Campinas. A Tabela $\mathrm{X}$ indica quais foram os canais analisados e viabilizados para atingir este objetivo. 
TABELA X

MUNDANÇAS NA ALOCAÇão INICIAL PARA CONFIGURAÇÃo DE REDES $S F N$

\begin{tabular}{|c|l|}
\hline Americana & $\begin{array}{l}\text { Radiobrás (15) } \\
\text { TV Carioba (24) }\end{array}$ \\
\hline Hortolândia & Fundação Padre Anchieta (59) \\
\hline Indaiatuba & Radiobrás (15) \\
\hline $\begin{array}{c}\text { Santa Bárbara } \\
\text { D'Oeste }\end{array}$ & Empresa Paulista de Televisão (13) \\
\hline Sumaré & Fundação Século Vinte e Um (54) \\
\hline
\end{tabular}

Os estudos de viabilidade foram feitos utilizando-se o software CPqD Análise de Interferências - Versão 1.0.0.0, desenvolvido pelo Grupo de Pesquisa do CPqD ao qual está vinculado um dos autores deste artigo. Apresentamos somente uma das simulações feitas no estudo global de casos acima tratado, e que pode ser visualizado na Figura 3.

Os círculos apresentados na Figura 3 se referem à indicação do campo protegido dos canais em estudo.

Para análise de viabilidade de configuração de redes SFN, também foi levado em consideração a distância entre os municípios da microrregião de modo a verificar se estas distâncias, apresentadas na Tabela XI, impediriam a configuração deste tipo de rede, o que não ocorreu.

TABELA XI

DISTÂNCIAS ENTRE MUNICÍPIOS NECESSÁRIAS AOS ESTUDOS

\begin{tabular}{|l|c|}
\hline \multicolumn{1}{|c|}{ Municípios } & Distância \\
\hline Campinas - Santa Bárbara D’Oeste & $40 \mathrm{~km}$ \\
\hline Campinas - Sumaré & $23 \mathrm{~km}$ \\
\hline Campinas - Hortolândia & $17 \mathrm{~km}$ \\
\hline Campinas - Valinhos & $10 \mathrm{Km}$ \\
\hline Valinhos - Santa Bárbara D’Oeste & $49 \mathrm{~km}$ \\
\hline Hortolândia - Santa Bárbara D’Oeste & $23 \mathrm{~km}$ \\
\hline Santa Bárbara D’Oeste - Americana & $9 \mathrm{~km}$ \\
\hline Indaiatuba - Americana & $41 \mathrm{~km}$ \\
\hline
\end{tabular}

\begin{tabular}{|c|c|c|c|c|c|}
\hline \multicolumn{3}{|l|}{ Proposto } & \multicolumn{3}{|c|}{ Existente } \\
\hline \multicolumn{3}{|c|}{ [0] SP_Americana_24 } & \multicolumn{2}{|c|}{ SP_Campinas_24 } & $\nabla$ \\
\hline \multicolumn{3}{|c|}{$\begin{array}{l}\text { ॠ Campo Protegido } \\
\Gamma \text { Campo Interferente } \\
\Gamma \text { Interferência do Existente } \\
\Gamma \text { Relevo } \\
\text { ॠ Contorno Protegido Teórico } \\
\square \text { Contorno Interferente Teórico }\end{array}$} & \multicolumn{3}{|c|}{$\begin{array}{l}\sqrt{ } \text { Campo Protegido } \\
\Gamma \text { Campo Interferente } \\
\Gamma \text { Interferência do Proposto } \\
\Gamma \text { Relevo } \\
\square \text { Contorno Protegido Teórico } \\
\square \text { Contorno Interferente Teórico }\end{array}$} \\
\hline \multicolumn{6}{|c|}{ Informaçōes do Estudo- } \\
\hline \multicolumn{3}{|c|}{ Modelo: Ponto a Ponto } & \multicolumn{3}{|c|}{ Plano: TV (Digital) } \\
\hline \multicolumn{3}{|c|}{ Raio de Busca: $200 \mathrm{~km}$} & \multicolumn{3}{|c|}{ ERP $[150 \mathrm{~m}]: 0,08 \mathrm{~kW}$} \\
\hline \multicolumn{3}{|c|}{ Resolução de Cálculo: $100 \mathrm{~m}$} & \multicolumn{3}{|c|}{ ERP (Instalada): $0 \mathrm{~kW}$} \\
\hline \multicolumn{3}{|c|}{ Latitude: $\cdot 22^{\circ} 44^{\prime} 21^{\prime \prime}$ - Longitude $-47^{\circ} 19^{\prime} 53^{\prime \prime}$} & \multicolumn{3}{|c|}{ CBT+HCF: NMT $+150 \mathrm{~m}$} \\
\hline \multicolumn{2}{|c|}{ Diagrama da Antena: Omni } & \multicolumn{2}{|c|}{ Orientação: 0} & \multicolumn{2}{|c|}{ Limitação: 0} \\
\hline 国 Avançadas... & 2. Foto de Satélite & & Plotar & $\mathbf{X}$ Cancelar & Siuda \\
\hline
\end{tabular}

Fig. 2. Exemplo de tela de configuração do software de simulação.

\section{CONCLUSÃo}

A necessidade de otimização do uso do espectro é uma realidade e, portanto, as tecnologias e técnicas disponíveis devem ser utilizadas para que não hajam desperdícios de recursos. Este artigo apresenta pela primeira vez um enfoque diferente para a alocação de canais de TV Digital para o nosso País. Até então eram feitas considerações somente sobre aspectos técnicos. A idéia do artigo é propor uma estratégia em que uma emissora de televisão que tenha a mesma programação dentro de uma microrregião utilize somente um canal de televisão para transmitir esta programação nesta região. A estratégia proposta tem como resultado o aumento da eficiência no uso do espectro de radiofrequiências. Foi analisada a aplicação desta estratégia na microrregião de Campinas, SP, onde a necessidade de canais para alocar todas as emissoras tem uma redução abrupta de 28 para 15 canais.

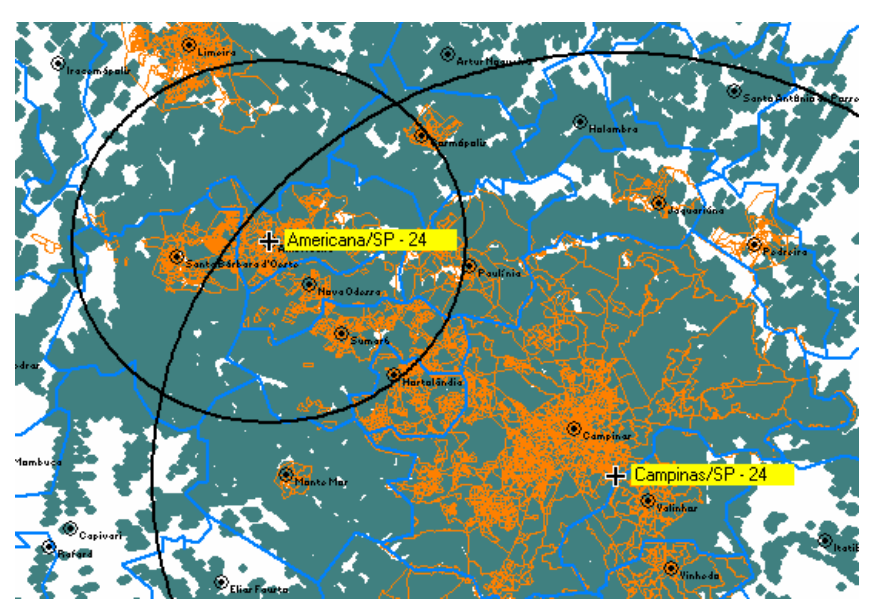

Fig. 3. Plot $2 D$ de uma das Simulações Realizadas.

\section{REFERÊNCIAS}

[1] AGÊNCIA NACIONAL DE TELECOMUNICAÇÕES. Decreto no 4.901, de 26 de novembro de 2003: Institui o Sistema Brasileiro de Televisão Digital - SBTVD, e dá outras providências. Brasília, 2003.

[2] AGÊNCIA NACIONAL DE TELECOMUNICAÇÕES. Resolução no 398, de 7 de abril de 2005: Alteração do regulamento técnico para a prestação do serviço de radiodifusão de sons e imagens e do serviço de retransmissão de televisão, aprovado pela Resolução ANATEL No. 284. Brasília, 2005.

[3] AGÊNCIA NACIONAL DE TELECOMUNICACÕES. Decreto no 5.820, de 29 de Junho de 2006: Dispõe sobre a implantação do SBTVD-T, estabelece diretrizes para a transição do sistema de transmissão analógica para o sistema de transmissão digital do serviço de radiodifusão de sons e imagens e do serviço de retransmissão de televisão, e dá outras providências. Brasília, 2006.

[4] Centro de Pesquisa e Desenvolvimento - CPqD, "Planejamento de Canais de TV Digital', 2003, www.anatel.gov.br .

[5] AGÊNCIA NACIONAL DE TELECOMUNICAÇÕES. Resolução no 407, de 10 de junho de 2005: Aprova o Plano Básico de Distribuição de Canais de Televisão Digital - PBTVD. Brasília, 2005.

[6] S. Nakahara, S. Moriyama, T. Kuroda, M. Sasaki, S. Yamazaki, O. Yamada, "Efficient Use of Frequencies in Terrestrial ISDB System" IEEE Trans on Broadcasting, Vol. 42, No. 3, Sept. 1996.

[7] Y. Wu, E. Pliszka, B. Caron, P. Bouchard and G. Chouinard, "Comparison of terrestrial DTV transmission systems: the ATSC 8$V S B$, the DVB-T COFDM, and the ISDB-OFDM", IEEE Transactions on Broadcasting, Vol. 46, No. 2, pp. 101-113, June 2000.

[8] A. Mattsson, "Single Frequency Networks in DTV," IEEE Trans on Broadcasting”, Vol. 51, No. 4, Dec. 2005.

[9] ARIB STD-B31 V. 1.6, "Transmission System for Digital Terrestrial Television Broadcasting ARIB Standard", Association of Radio Industries and Businesses, Nov. 30th , 2005. 